\title{
Experimental study of the thermochemical treatment of the low-grade coal prior to boiler combustion at coal-fired power station
}

\author{
Volodymyr Yemelianenko ${ }^{1, *}$, Vitalii Pertsevyi ${ }^{2}$, Oleksandr Zhevzhyk $^{2}$, Iryna Potapchuk ${ }^{1}$, \\ and Oleksandr Lutai $^{3}$ \\ ${ }^{1}$ Institute of Geotechnical Mechanics named by N. Poljakov of National Academy of Sciences of \\ Ukraine, 49005, Dnipro, Simferopolska Str., 2a, Ukraine \\ ${ }^{2}$ Dnipropetrovsk National University of Railway Transport named after Academician V. Lazaryan, \\ 49010, Dnipro, Lazaryan Str., 2, Ukraine \\ ${ }^{3}$ Institute of Strategic Technologies named after academician S.M. Koniukhov, 49005, Dnipro, \\ Simferopolska Str., 15, Ukraine
}

\begin{abstract}
Analysis of the perspectives of the coal fuel for thermal power plants is carried out. The necessity of the experimental study for temperature measurement in the boiler furnace. The results of the experimental study are presented: temperature change over time at the burner outlet for different constant pressure value of the backlighting gas, dependence of the temperature at the burner outlet from the backlighting gas pressure for constant concentration value of pulverized coal in coal-air mixture, dependence of the temperature at the burner outlet from the concentration of pulverized coal in coal-air mixture for constant value of the backlighting gas pressure, temperature measurements for constant backlighting gas pressure value, constant value of the concentration of pulverized coal in coal-air mixture when plasmatron is switched and operates for some time range. The results of the study could be applied to the solid fuel treatment for different thermal units.
\end{abstract}

\section{Introduction}

Geological reserves of low-grade coal have been explored for many years ahead, while its production will not only be preserved, but also due to the rapid depletion of oil and gas reserves, will increase in the near future.

At present, about 40 boiler units of different capacities of domestic thermal power plants (TPP) operate on a low-grade coal of the anthracite dust coal type (ADC). Traditionally, combustion of low-grade coal of the anthracite type at TPP is carried out in a coal dust flame with fuel backlighting by oil and natural gas.

In this case, there is a significant mechanical underburning and the presence of harmful emissions into the atmosphere take place.

The use of coal with a high content of volatile substances (more than $16 \%$ ) in boilers of

*Corresponding author: VIEmelianenko@nas.gov.ua 
TPP intended for combustion of ADC, due to the features of the combustion process, the design of the boiler unit, is not allowed without significant reconstruction of the boiler and coal dust-preparation equipment.

The solution of the problem of highly efficient combustion of low-grade coal with significant ash content in TPP boilers is provided by the new technology given in this paper.

The essence of the technology is the thermochemical fuel treatment (TCFT) before it enters the combustion space of the boiler.

TCFT technology consists of high-speed high-temperature heating and partial coal gasification within a special reactor.

Due to this, earlier ignition of coal particles of small and medium size, rational distribution of ignition zones, burning and burning down of fuel particles in the reactor, burner and boiler are achieved, and as a result:

- reduction of backlighting fuel consumption;

- reduction of coal mechanical underburning;

- reduction of harmful emissions into the atmosphere.

\section{Temperature measurements at the burner outlet of the boiler}

The processes that take place in modern power plants are characterized by the presence within their workspace of a multiphase medium, a wide range of temperature changes, chemical transformations, both in gas and solid phases, complicated aerodynamics of the working medium, high degree of turbulence, heterogeneity of parameters within the workspace.

Existing mathematical models do not allow to determine with sufficient accuracy the parameters of these processes. One of the ways to study and select the rational parameters of high-temperature processes, energy and technical characteristics of power plants is to conduct experimental research.

To compare the TCFT technology and the existing technology of coal combustion with backlighting by natural gas, the method of estimating local heat fluxes, that are perceived by the sections of the TPP-210 type boilers, is used.

Heat exchange tubes of the pulverized coal burner arch equipped with the plasma reactor were selected (Fig. 1) for experimental study.

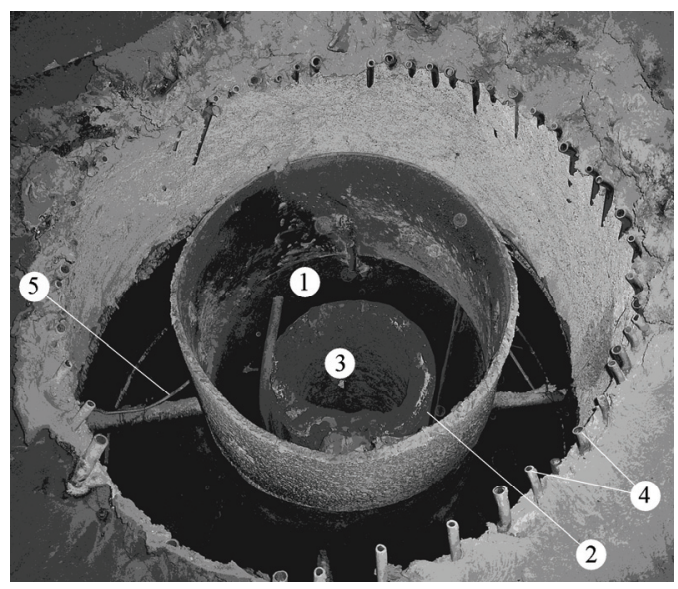

Fig. 1. View from the boiler furnace to the coal burner arch equipped by the plasma reactor: 1- inner surface of the burner; 2- outer surface of the heat exchange tube; 3-inner space of the heat exchange tube; 4- branch pipes of the gas burners; 5- pipe with chromel-alumel thermocouple. 
The assessment of local heat fluxes was carried out using temperature sensors on the outer surface of the heat exchange tubes and an optoelectronic monitoring system for controling the pulverized coal burner on the basis of portable water cooled video probes.

The plasma reactor is designed to stabilize combustion of a flame when the coal dust burning is lower than a predetermined level at the control point of the boiler or backlighting of low-grade dust of coal fuel, that is, thermochemical treatment of fuel before it enters the boiler furnace.

The reactor consists of a frame, plasmatron, a damper and a heat exchange tube. The frame contains a flange, a cap, a pipe course, guides for a heat exchange tube and guides for tie-rods of a damper. The heat exchange tube mounted on the tie-rods of the frame along the axis of the burner is made of a steel pipe and is lined inside with a refractory material. The frame cap along the axis of the burner has a hole with sealing elements for installing the plasmatron. The damper is installed at the heat exchange tube. By means of the damper during the plasma reactor operation, it is possible to change the consumption of coal dust entering the annular gap between the inner surface of the burner and the outer surface of the heat exchange tube, as well as in the inner space of the heat exchange tube. In this way it is possible to control the consumption and temperature of the coal dust ignition and its subsequent combustion within the plasma reactor.

The heat exchangers of the pulverized coal burner (Fig. 2) perceive heat fluxes from the furnace boiler, coal dust burner, flame of the burning natural gas supplied from the branch pipes of the gas burners.

Since the heat flux from the boiler furnace is almost stationary during the experiment, the thermocouples set up on the heat exchangers as shown in Figure 2, perceive the fluctuations in the heat fluxes from the coal dust burner and the flame of the burning natural gas. The fluctuations in the heat flux from the coal dust burner are due to the thermochemical treatment of the fuel. The fluctuations of the heat flux from the flame of the burning natural gas are due to the pressure value change of the natural gas for backlighting of the coal dust torch.

View from the boiler to the burner
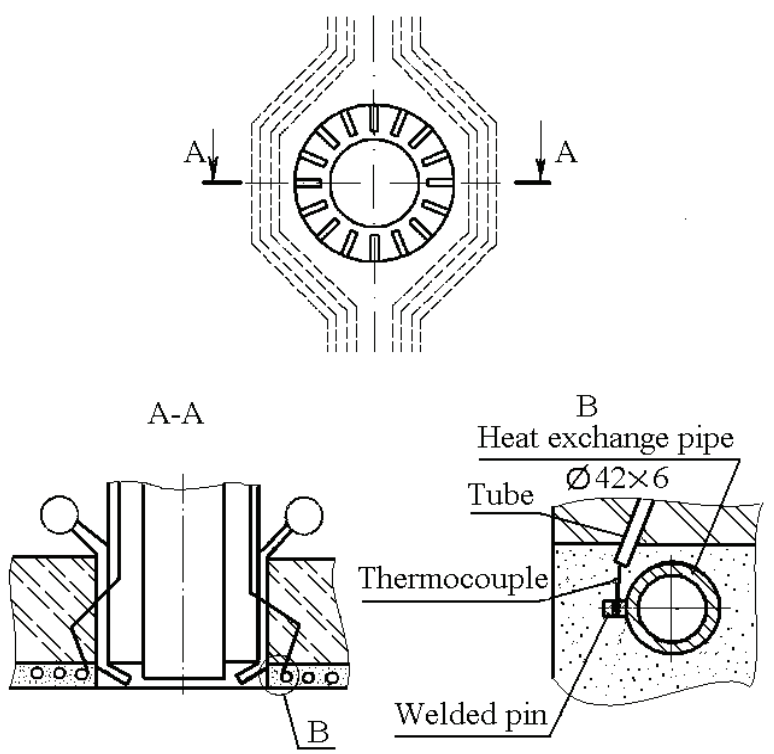

Fig. 2. Thermocouple set up at the outer surface of the heat exchangers inside the arc of the pulverized coal burner. 
In the experimental study devices for measurement of the operating parameters of the boiler were used as follows:

- chromel-alumel thermocouples were located in the boiler at the outlet of the burner arch, they were welded on heat exchange pipes (bypass pipes of the boiler furnace);

- another chromel-alumel thermocouple were located inside a coal-air mixture swirler of the burner;

- the backlighting gas pressure entering the burner was measured by means of the manometer located at the board near the boiler;

- the pressure of the primary air entering the burner was measured by means of the manometer located at the board near the boiler;

- the pressure of the secondary air entering the burner was measured by means of the manometer located at the board near the boiler.

\subsection{Temperature measurements at the outlet of the pulverized coal burner arch for different pressure values}

The results of the experimental study are shown in Figure 3 and Figure 4.

The results of the experimental investigation of the temperature change over time at the burner outlet are as follows:

- for constant values of the backlighting gas pressure the temperature oscillations at the burner outlet within the range $10-30^{\circ} \mathrm{C}$ with time period $40-60 \mathrm{~s}$ were observed;

- backlighting gas pressure increasing leads to the increasing of the temperature at the burner outlet as well (Fig. 3 and Fig. 4).

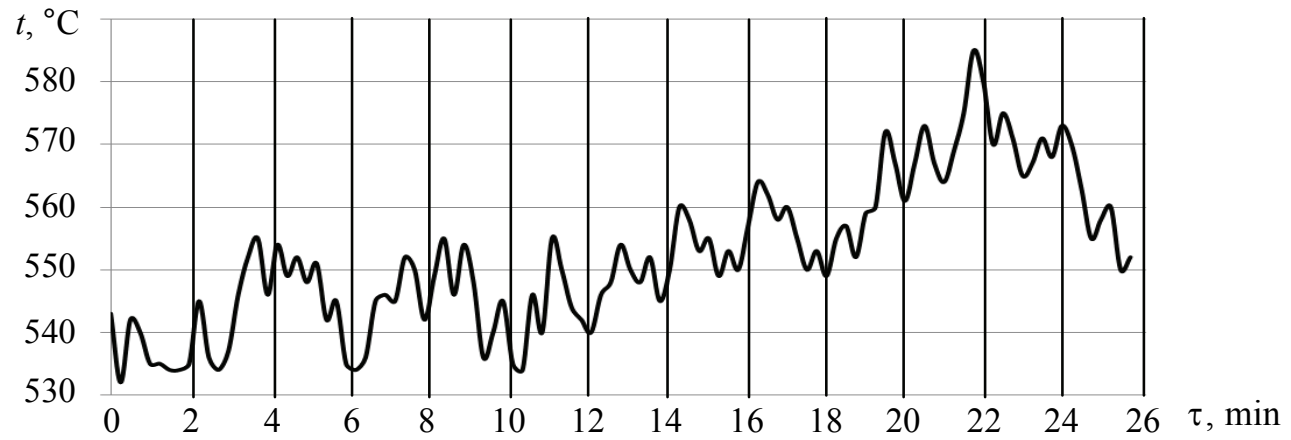

Fig. 3. Temperature change over time at the burner outlet for gauge pressure $4 \mathrm{kPa}$ of the backlighting gas.

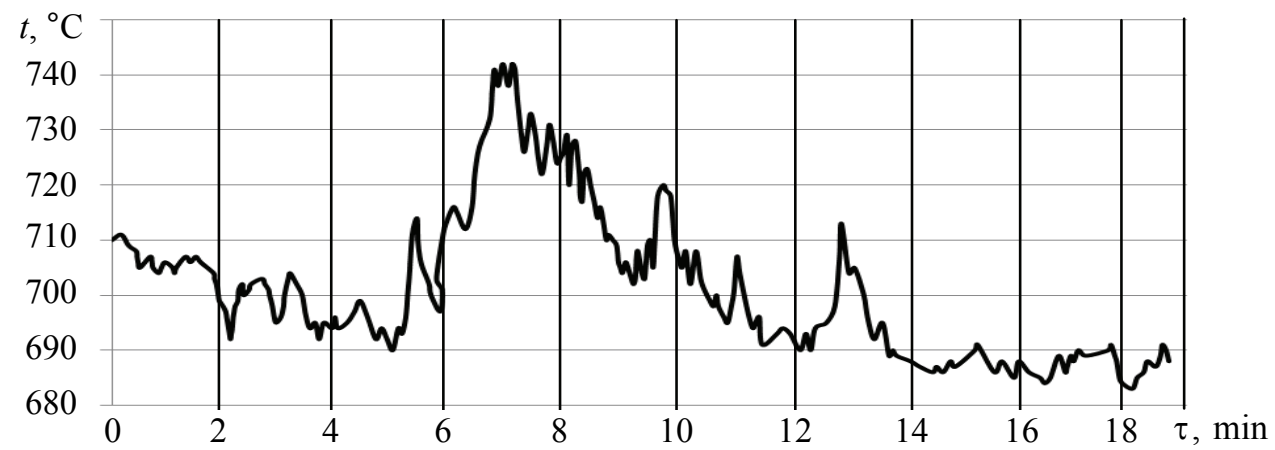

Fig. 4. Temperature change over time at the burner outlet for gauge pressure $7.5 \mathrm{kPa}$ of the backlighting gas. 


\subsection{Temperature measurements at the outlet of the pulverized coal burner arch for variable pressure values}

Conditions of the experimental investigations were as follows: primary air gauge pressure $1374 \mathrm{~Pa}$, secondary air gauge pressure $250 \mathrm{~Pa}$, initial temperature of the coal dust $50{ }^{\circ} \mathrm{C}$, temperature of the primary air $290{ }^{\circ} \mathrm{C}$, anthracite dust coal parameters: $\mathrm{A}^{\mathrm{p}}=21.8 \%$, $\mathrm{W}^{\mathrm{p}}=9.1 \%, \mathrm{Q}_{\mathrm{H}}{ }^{\mathrm{p}}=22.6 \mathrm{MJ} / \mathrm{kg}$. Parameters kept under control: temperature at the outer surface of the heat exchange tube, backlighting gas pressure, coal-air mixture temperature at the swirler inlet, concentration value of pulverized coal in coal-air mixture.

The results of the experimental study are shown in Figures 5-7.

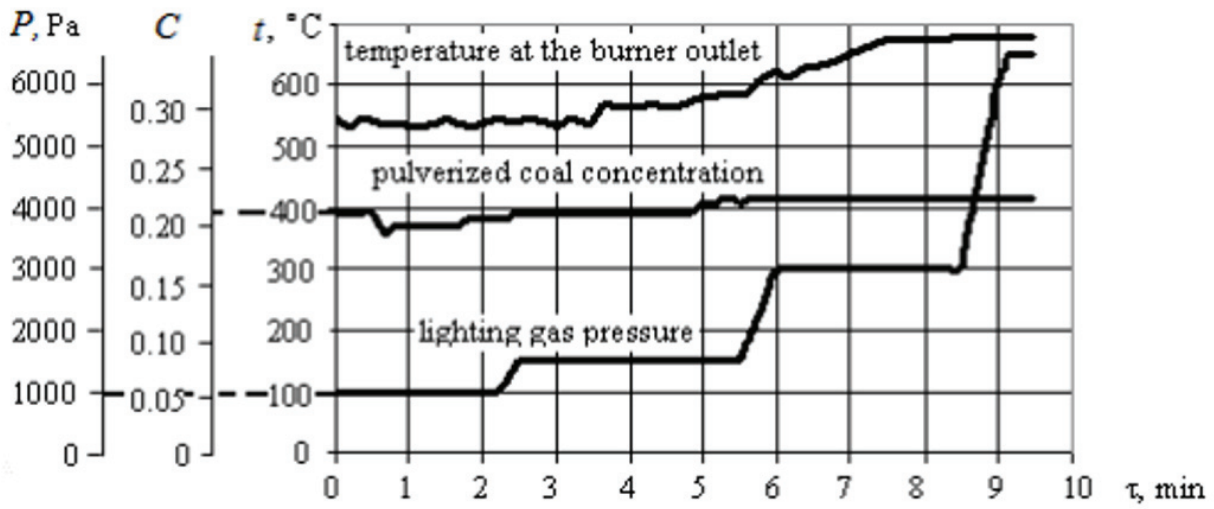

Fig. 5. Dependence of the temperature $t$ at the burner outlet from the backlighting gas pressure $P$ for constant concentration value $C$ of pulverized coal in coal-air mixture.

The results of the experimental investigation are shown in Figure 5 as follows:

- initial value of the backlighting gas pressure $1000 \mathrm{~Pa}$, terminal value of the backlighting gas pressure $6500 \mathrm{~Pa}$;

- backlighting gas pressure increasing by 6.5 times (from $1000 \mathrm{~Pa}$ up to $6500 \mathrm{~Pa}$ ) causes augmentation of the temperature at the outlet of the pulverized coal burner arch by $137^{\circ} \mathrm{C}$, i.e. by $25 \%$ (from $543{ }^{\circ} \mathrm{C}$ up to $680{ }^{\circ} \mathrm{C}$ ).

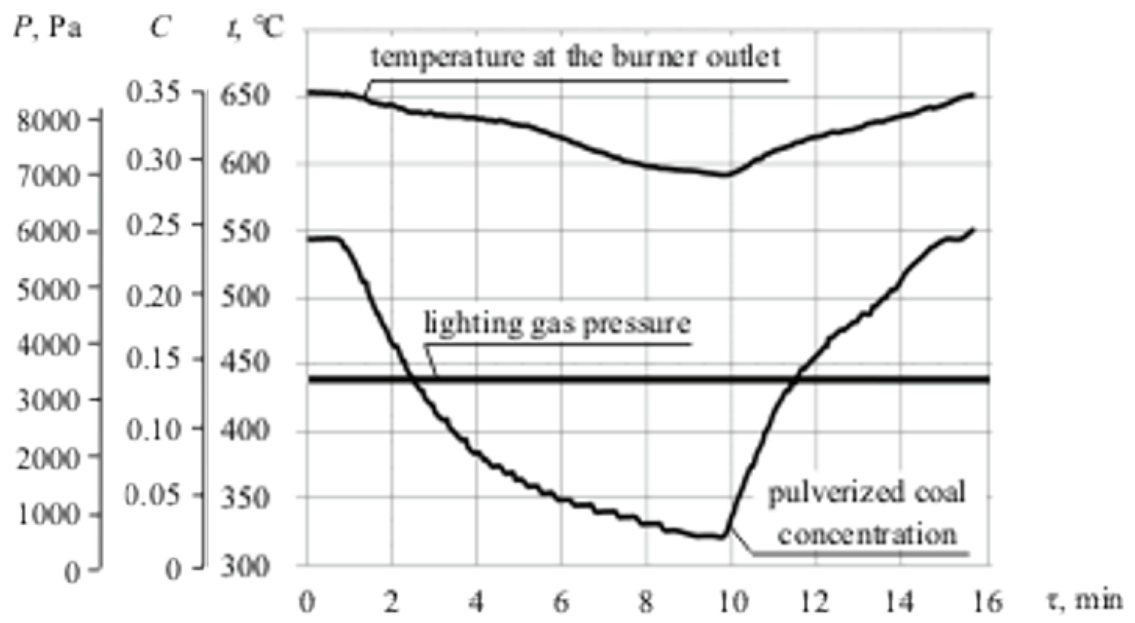

Fig. 6. Dependence of the temperature $t$ at the burner outlet from the concentration $C$ of pulverized coal in coal-air mixture for constant value of the backlighting gas pressure $P$.

The results of the experimental investigation are shown in Figure 6 as follows: 
- decreasing of the concentration of pulverized coal in coal-air mixture by 11 times (from $0.244 \mathrm{~kg} / \mathrm{kg}$ up to $0.022 \mathrm{~kg} / \mathrm{kg}$ ) leads to the decreasing of the temperature at the outlet of the pulverized coal burner arch by $62{ }^{\circ} \mathrm{C}$, i.e. by $9.5 \%$.

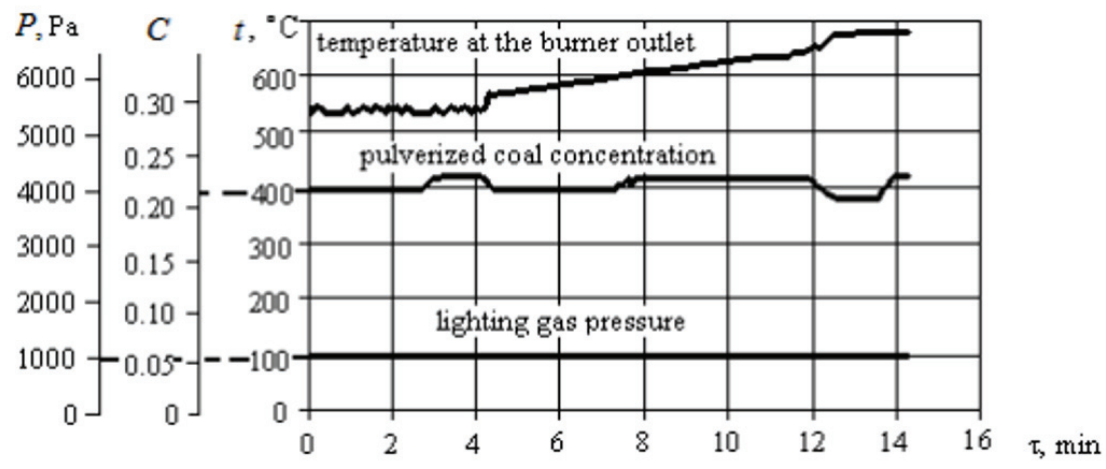

Fig. 7. Temperature measurements $t$ for backlighting gas pressure value $1000 \mathrm{~Pa}$, constant value of the concentration $C$ of pulverized coal in coal-air mixture when plasmatron is switched and operates after $\tau=2 \mathrm{~min}$.

The results of the experimental investigation are shown in Figure 7. It is obvious that after $\tau=4 \mathrm{~min}$, the temperature at the burner outlet began to increase from $550{ }^{\circ} \mathrm{C}$ to $680{ }^{\circ} \mathrm{C}$.

\subsection{The results of the visual control of the heat flux inside the pulverized coal burner arch synchronized with temperature measurements at the burner outlet}

The results of the visual control of the heat flux inside the pulverized coal burner arch are shown in Figure 8 and Figure 9. View to the pulverized coal burner arch from the access hatrch of the secondary air swirler is depicted in Figure 8 and Figure 9.

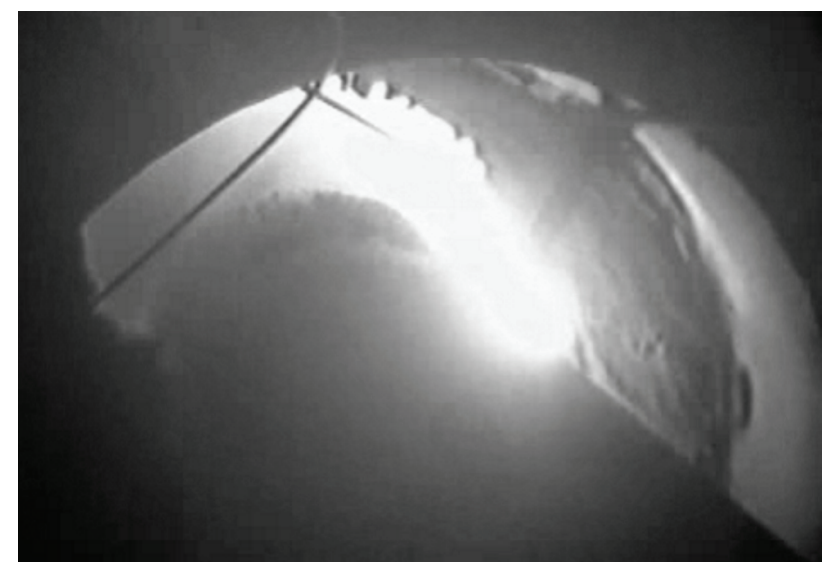

Fig. 8. Unignited coal dust supplies to the boiler when plasmatron is switched off for time range $\tau=0$ $2 \mathrm{~min}$.

For the backlighting gas pressure value $1000 \mathrm{~Pa}$ (lowest pressure value conditioned by the process) and constant value of the coal concentration in coal-air mixture $150 \mathrm{~kW}$ plasmatron (current $220 \mathrm{~A}$, voltage $680 \mathrm{~V}$, air consumption $26 \mathrm{~g} / \mathrm{s}$ ) has provided heating of the coal dust up to the ignition temperature that was confirmed by the visual control results of the heat flux within the pulverized coal burner arch as well as has formed heat flux 
within the pulverized coal burner equal to the heat flux created by the backlighting gas that was confirmed by the temperature measurements at the burner outlet.

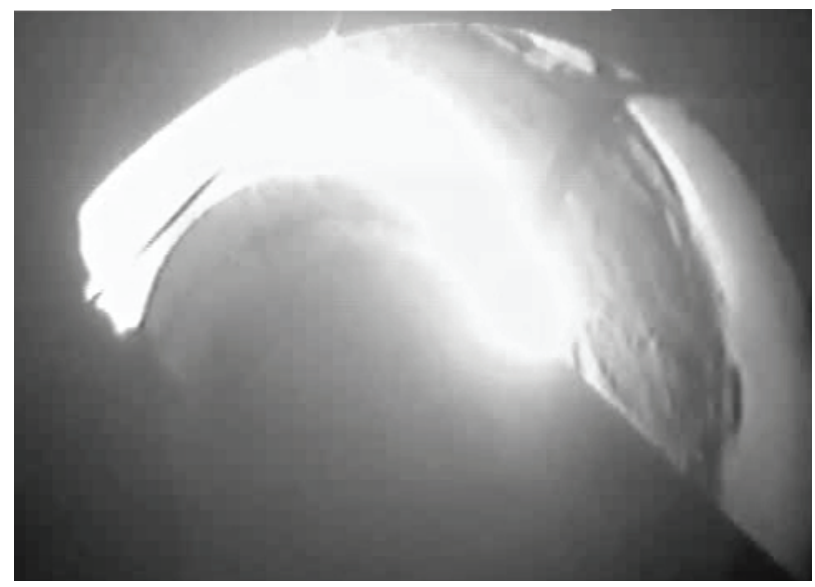

Fig. 9. Coal dust ignited in $10 \mathrm{~min}$. after the plasmatron was switched on supplies to the boiler for time range $\tau=12-14 \mathrm{~min}$.

\section{Conclusions}

For conditions that match to experimental study $150 \mathrm{~kW}$ plasmatron is able to provide heating of the coal dust up to the ignition temperature and able to form heat flux within plasma reactor that equals to that one created by the backlighting gas.

Strong dependence between the temperature at the outer surface of the heat exchangers and backlight gas pressure as well as coal concentration in coal-air mixture was observed. The results of the experimental study could be useful for parameters set up of the plasma reactors thermochemical treatment of the low-grade coal prior to boiler combustion.

\section{References}

1. Messerle, V.E., Ustimenko, A.B. (2015). Plasma treatment of the gaseous and solid fuels, Sovremennaya nauka. Issledovaniya, idei, rezultaty, tekhnologii, 1 (16), 200 206

2. Bulat, A.F., Voloshin, A.I., Kudinov, P.I. (2002). Technology of the coal dust fuel preparation by means of plasma. In: Trudy III rossiyskoy natsionalnoy konferentsii po teploobmenu, 3, 173-176

3. Kukota, Yu.P., Bondzik, D.L., Dynaevskaia, N.I. (2004). Ignition of the high ash content anthracites for their torch combustion by means of plasma, Promyslova tekhnologiia, 6, 146 - 151

4. Voloshin, A.I., Zhevzhik, A.V., Goriachkin, V.N., Potapchuk, I.Yu. (2013). Stydy uneven concentration of coal dust particles in continuous-flow horizontal channel of thermochemical fuel preparation reactor, Geoteknichna Mekhanika [Geo-Technical Mechanics], 109, 120 - 129

5. Yemelianenko, V.I., Malik, P.V., Livitan, N.V. (2011). Influence of the coal dust concentration in coal-air mixture on the specific energy consumption during its ignition by means of plasma, Metallurgiyna Teploteknika, 3 (18), 90 - 95

6. Kotliarov, O.L., Yatsenko, V.P. (2007). Numerical study of the plasma-chemical treatment of the low-grade coal dust prior to its combustion in the boiler furnace, 
Problemy zahalnoi energetyky, 87- 95

7. Grebenkov, L.Yu., Nazarov, M.N. (2007). Study of the local heat transfer in the furnace of the boiler P-67 by means of diagnostics system. In: Trudy IV nauchno-prakticheskoy konferentsii "Mineralnaya chast topliva, shlakovanie, zagriaznenie I ochistka kotlov", $10,18-20$

8. Yemelianenko, V.I. (2017). Plasma reactor for coal dust burner of the TPP-210 boiler, Geoteknichna Mekhanika [Geo-Technical Mechanics], 132, 173 - 182 